\title{
Apolipoprotein M T-778C polymorphism is associated with serum lipid levels and the risk of coronary artery disease in the Chinese population: a meta-analysis
}

Zhi Zhang ${ }^{2+}$, Guang $\mathrm{Chu}^{2+}$ and Rui-Xing Yin ${ }^{1 *}$

\begin{abstract}
Background: The apolipoprotein M (APOM) T-778C gene polymorphism has been associated with serum lipid levels and the risk of coronary artery disease (CAD), but the results are inconclusive. The purpose of this metaanalysis was to detect the association between the APOM T-778C polymorphism and serum lipid levels and the risk of CAD in the Chinese population.

Methods: Databases of MEDLINE, EMBASE, the Cochrane Library and CNKI were systematically searched. Data were extracted using standardized methods. The association was assessed by mean difference (MD) with 95\% confidence intervals (Cl) or odds ratio (OR) with $95 \% \mathrm{Cl}$.

Results: Ten studies with 4,413 patients were included in this meta-analysis. Pooled effects indicated that $\mathrm{CT}+\mathrm{CC}$ group had higher levels of total cholesterol (TC) (MD:-0.36, 95\% Cl: $-0.53--0.19, P<0.0001)$ and low-density lipoprotein cholesterol (LDL-C) (MD: $-0.08,95 \% \mathrm{Cl}:-0.16--0.01, P=0.03)$ than $\Pi$ group. There was no difference in the levels of triglyceride (MD: $0.06,95 \% \mathrm{Cl}:-0.04-0.15, P=0.22)$ and high-density lipoprotein cholesterol (MD: 0.00 , 95\% Cl: $-0.03-0.03, P=0.93$ ) between $\Pi$ and $C T+C C$ groups. Pooled effects showed that CAD group had higher $\mathrm{CT}+\mathrm{CC}$ genotype frequency than control group (OR: 1.97, 95\% Cl: $1.62-2.39, P<0.00001$; heterogeneity test $x^{2}=$ $\left.2.96, P=0.71, P^{2}=0 \%\right)$.
\end{abstract}

Conclusions: The results of the current meta-analysis show that the CT+CC group has higher levels of TC and LDL$\mathrm{C}$ than the $\Pi$ group. Moreover, there is also a prominent association between APOM T-778C polymorphism and the risk of $C A D$ in the Chinese population, the $C T+C C$ genotype is associated with increased risk of CAD.

\section{Introduction}

Coronary artery disease (CAD) continues to be the leading cause of morbidity and mortality among adults nowadays [1]. Many studies have proved that serum lipid concentrations are strongly correlated to the risk of CAD, such as a low concentration of high-density lipoprotein cholesterol (HDL-C) [2,3], and high levels of total cholesterol (TC) [4], triglyceride (TG) [5], low-density lipoprotein cholesterol (LDL-C) [6], and apolipoprotein (Apo) B

\footnotetext{
* Correspondence: yinruixing@163.com

${ }^{\dagger}$ Equal contributors

'Department of Cardiology, Institute of Cardiovascular Diseases, The First Affiliated Hospital, Guangxi Medical University, Nanning 530021, Guangxi, People's Republic of China

Full list of author information is available at the end of the article
}

$[7,8]$. However, it is widely accepted that dyslipidemia and CAD are caused by multiple environmental and genetic factors and their interactions [9].

Association of different genes and CAD and/or dyslipidemia has been widely examined. Recently, apolipoprotein $\mathrm{M}$ (APOM) gene has been reported relevant to CAD and dyslipidemia [10]. APOM gene is located in p21.31 on human chromosome 6 (chromosome 17, in mouse). Human APOM cDNA (734 base pairs) encodes 188 -amino acid residue-long protein [11]. APOM is mainly associated with HDL-C and lesser extent with TG-rich lipoproteins, ApoB-containing lipoproteins, low and very low-density lipoprotein (VLDL). It has been also demonstrated that APOM plays an important role
C Biomed Central

(c) 2013 Zhang et al.; licensee BioMed Central Ltd. This is an Open Access article distributed under the terms of the Creative Commons Attribution License (http://creativecommons.org/licenses/by/2.0), which permits unrestricted use, distribution, and reproduction in any medium, provided the original work is properly cited. 
in reverse cholesterol transport [12]. It is exclusively expressed in liver and in kidney [13].

Recent studies have showed that the APOM T-778C (rs805296) is valid in the Han Chinese and associated with serum lipid levels and the risk of CAD, but the results are inconclusive [14-23]. It may be partially due to the fact that the APOM gene was a minor gene for risk of dyslipidemia and/or the relatively small sample size in each of the published studies. Therefore, we performed a meta-analysis of the published studies to derive a more precise estimation of the association.

\section{Materials and methods}

\section{Search strategy}

All studies that reported the association between the APOM T-778C polymorphism and serum lipid levels and/or the risk of CAD and published in English or in Chinese before May, 2013 were identified by comprehensive computer-based searches of MEDLINE via PubMed (from 1950 to May 2013), EMBASE (1980 to May 2013), the Cochrane Library database (Cochrane Central Register of Controlled Trials, from 1991 to May 2013) and China National Knowledge Infrastructure (CNKI). The following key words were used: "Apolipoprotein M," "APOM," "rs805296 (T-778C) polymorphism", "dyslipidemia" and "serum lipid level", "coronary artery disease". The above search strategy described was used to obtain titles and abstracts of studies that may have been relevant to this review. The titles and abstracts were screened independently by two authors ( $\mathrm{Z}$ Zhang and G Chu), who discarded studies that were not applicable. When multiple reports from the same patients were found, only the study with the most complete data set was included in the metaanalysis. But duplicate patients of different articles that have different types of data of outcomes were included both. Any disagreements were arbitrated by discussion with the third reviewer (R-X Yin).

\section{Included and excluded studies}

Two investigators reviewed all identified studies independently to determine whether an individual study was eligible for inclusion. The selection criteria for studies to be considered for this meta-analysis were as follows: (1) case-control studies published in peer-reviewed journals with full available text in English or in Chinese; (2) the APOM gene T-778C polymorphism and serum lipid levels and the risk of CAD; (3) reporting at least one relevant outcomes of association between genotype and serum lipid levels and the risk of CAD, serum lipid levels including TC, HDL-C, LDL-C, and TG. Excluded studies: (1) studies in which it was not possible to extract data from the published results and from the authors; and (2) studies that did not report appropriate outcomes were also excluded.

\section{Types of outcome measures}

(1) Relationship between serum lipid parameters and genotypes; (2) Relationship between the risk of CAD and genotypes; (3) Genotype freguency: TT and CT+CC; (4) Serum lipid parameters: TC, TG, HDL-C, and LDL-C.

\section{Data extraction and management}

Two investigators (Z Zhang and G Chu) independently extracted data according to the author details and the following information was extracted from each study: first author, year of publication, sample size, diagnostic criteria, study design, characteristics of controls, genotype information (number of genotypes, genotyping

Table 1 Newcastle - Ottawa quality assessment scale case-control studies

\begin{tabular}{|c|c|}
\hline Criteria & Score \\
\hline \multicolumn{2}{|l|}{ Selection } \\
\hline \multicolumn{2}{|l|}{ 1) Is the case definition adequate? } \\
\hline a) yes, with independent validation & is \\
\hline \multicolumn{2}{|l|}{ b) yes, eg record linkage or based on self reports } \\
\hline \multicolumn{2}{|l|}{ c) no description } \\
\hline \multicolumn{2}{|l|}{ 2) Representativeness of the cases } \\
\hline a) consecutive or obviously representative series of cases & is \\
\hline \multicolumn{2}{|l|}{ b) potential for selection biases or not stated } \\
\hline \multicolumn{2}{|l|}{ 3) Selection of controls } \\
\hline a) community controls & it \\
\hline \multicolumn{2}{|l|}{ b) hospital controls } \\
\hline \multicolumn{2}{|l|}{ c) no description } \\
\hline \multicolumn{2}{|l|}{ 4) Definition of controls } \\
\hline a) no history of disease (endpoint) & 访 \\
\hline \multicolumn{2}{|l|}{ b) no description of source } \\
\hline \multicolumn{2}{|l|}{ Comparability } \\
\hline \multicolumn{2}{|l|}{$\begin{array}{l}\text { 1) Comparability of cases and controls on the basis of the } \\
\text { design or analysis }\end{array}$} \\
\hline a) study controls for the most important factor & it \\
\hline b) study controls for any additional factor & is \\
\hline \multicolumn{2}{|l|}{ Exposure } \\
\hline \multicolumn{2}{|l|}{ 1) Ascertainment of exposure } \\
\hline a) secure record (eg surgical records) & 访 \\
\hline b) structured interview where blind to case/control status & is \\
\hline \multicolumn{2}{|l|}{ c) interview not blinded to case/control status } \\
\hline \multicolumn{2}{|l|}{ d) written self report or medical record only } \\
\hline \multicolumn{2}{|l|}{ e) no description } \\
\hline \multicolumn{2}{|l|}{ 2) Same method of ascertainment for cases and controls } \\
\hline a) yes & 访 \\
\hline \multicolumn{2}{|l|}{ b) no } \\
\hline \multicolumn{2}{|l|}{ 3) Non-response rate } \\
\hline a) same rate for both groups & 访 \\
\hline b) non respondents described & \\
\hline c) rate different and no designation & \\
\hline
\end{tabular}




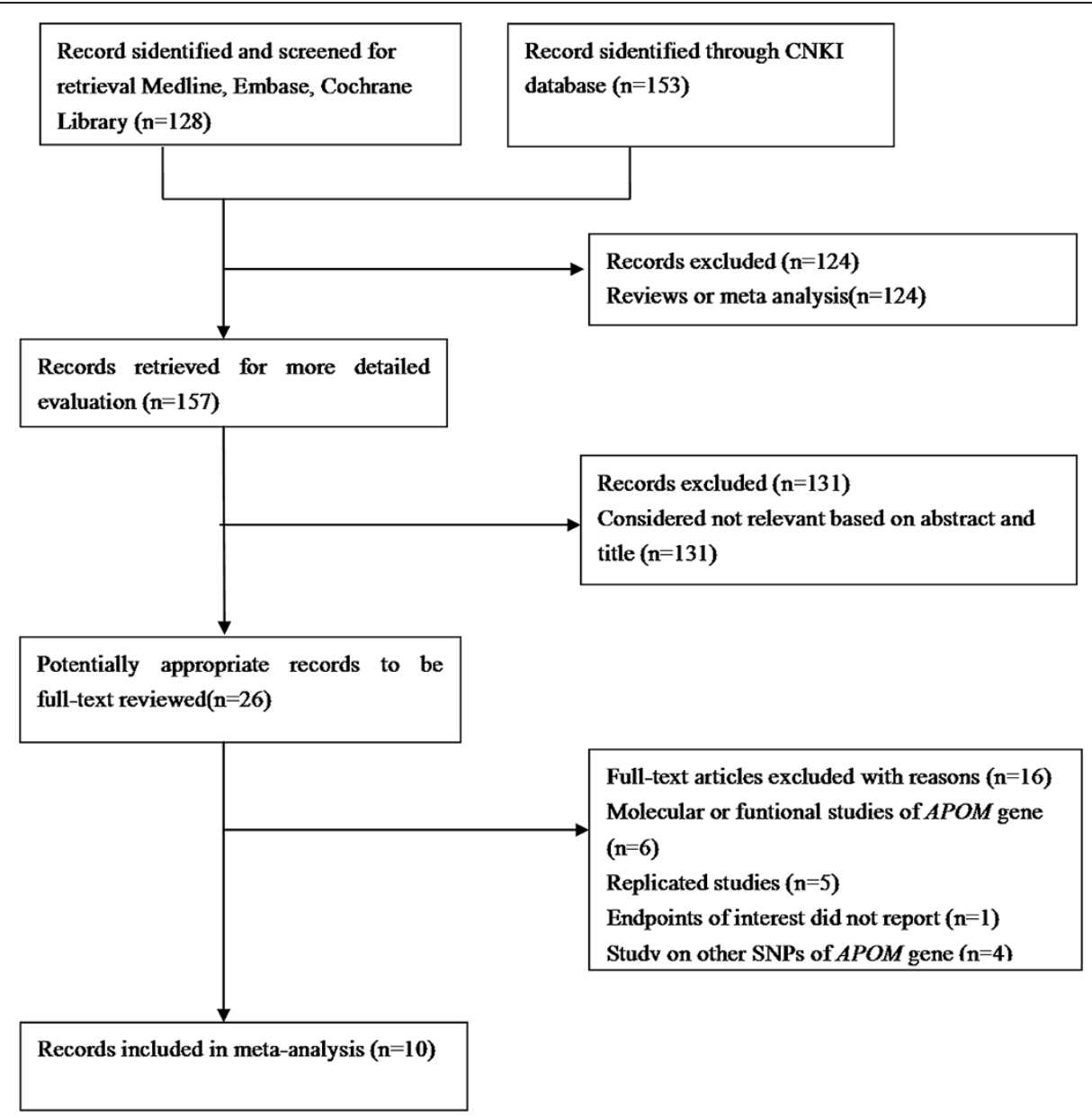

Figure 1 Flow chart showing study selection process.

method, genotype distribution in cases and controls), relationship between genotypes and serum lipid parameters and the risk of CAD. Discrepancies were resolved by discussion. When repeated publications of the same trial were identified, data were extracted from the repeated publications and reported as a single trial.

\section{Quality assessment}

The Newcastle-Ottawa Scale (NOS) [24] was used to assess the quality of each included study of the CAD group. Eight items were contained in the NOS (Table 1). It was categorized into three dimensions including selection, comparability, and exposure for case-control studies. Four, one and three items were contained in the selection, comparability and exposure; respectively. A star system was used to allow a semi-quantitative assessment of the study quality. A study can be awarded a maximum of one star for each numbered item within the selection and exposure categories. A maximum of two stars can be given for comparability. The NOS ranges from zero up to nine stars. High-, medium-, and poor-quality studies should be achieved more than seven, four to six, and less than four stars; respectively.

\section{Statistical analysis}

Allele frequencies of each study were determined by the allele counting method. Hardy-Weinberg equilibrium (HWE) for each single nucleotide polymorphism was assessed for the controls in each study using Pearson's Square $(P>0.05)$ [24]. We carried out statistical analysis by the Review Manager software 5.1.0 (updated in March 2011 by the Cochrane Collaboration). We examined the contrast of genetic model (TT vs. $\mathrm{CT}+\mathrm{CC})$ in serum lipid levels and genetic model $(\mathrm{CT}+\mathrm{CC} v s$. $\mathrm{TT}+\mathrm{CT}+\mathrm{CC})$ in the risk of $\mathrm{CAD}$. Continuous variables were expressed as mean difference (MD) with 95\% confidence intervals (CI). Dichotomous outcomes of the numbers of $\mathrm{CT}+\mathrm{CC}$ and $\mathrm{TT}+\mathrm{CT}+\mathrm{CC}$ genotypes in $\mathrm{CAD} /$ control values were expressed as odd ratio (OR) with $95 \% \mathrm{CI}$. The pooled effects were calculated using fixed effects models when there was no significant heterogeneity but the random effects model was analyzed to ensure robustness of the 
Table 2 Baseline characteristics of included studies

\begin{tabular}{|c|c|c|c|c|c|c|c|c|}
\hline \multirow[t]{2}{*}{ Study } & \multirow{2}{*}{ Year } & \multirow{2}{*}{$\begin{array}{l}\text { Eligible subjects } \\
\text { (case/control) }\end{array}$} & \multicolumn{2}{|c|}{ Age (years) } & \multicolumn{2}{|l|}{ Populations } & \multirow{2}{*}{ Method } & \multirow{2}{*}{ Outcome } \\
\hline & & & Case & Control & Case & Control & & \\
\hline Jiao et al. [15] & 2007 & $118 / 225$ & $61.8 \pm 11.4$ & $60.4 \pm 12.7$ & $\begin{array}{l}\text { CAD patients had at least } 30 \% \text { stenos is determined } \\
\text { angiographically in at least one of the major } \\
\text { segments of coronary arteries, the right coronary } \\
\text { artery, left circumflex, or left anterior descending } \\
\text { arteries. }\end{array}$ & Hospital-based & PCR-RFLP & $\begin{array}{l}\text { TC,TG, HDL-C, } \\
\text { LDL-C }\end{array}$ \\
\hline Zhao et al. [21] & 2011 & $314 / 389$ & $64.43 \pm 8.48$ & $63.93 \pm 6.86$ & $\begin{array}{l}\text { Ischemic stroke patients included having a sudden } \\
\text { loss of global or focal cerebral function, and } \\
\text { corresponding infarction confirmed by brain } \\
\text { imaging with a computed tomography scan and/or } \\
\text { magnetic resonance imaging. }\end{array}$ & Hospital-based & PCR, SNaPshot & $\begin{array}{l}\text { TC,TG, HDL-C, } \\
\text { LDL-C }\end{array}$ \\
\hline Zheng et al. [22] & 2009 & $126 / 118$ & $62.5 \pm 9.4$ & $63.0 \pm 10.8$ & $\begin{array}{l}\text { Patients that diagnosed as CAD according to the } \\
\text { results of angiography (a lesion was classed as } \\
\text { being significant when stenosis was }>50 \% \text { ). }\end{array}$ & Hospital-based & real-time PCR & $\begin{array}{l}\text { TC,TG, HDL-C, } \\
\text { LDL-C, ) }\end{array}$ \\
\hline Niu et al. [18] & 2006 & $170 / 156$ & $55.5 \pm 13.2$ & $56.2 \pm 9.7$ & $\begin{array}{l}\text { T2D patients were diagnosed according to the } \\
\text { criteria of the World Health Organization (1999). }\end{array}$ & Hospital-based & PCR-RFLP & $\mathrm{TC}, \mathrm{TG}$ \\
\hline Wu et al. [20] & 2009 & $117 / 316$ & $22.8 \pm 14.5$ & $63.1 \pm 9.7$ & $\begin{array}{l}\text { T1D patients were diagnosed according to the } \\
\text { criteria of the World Health Organization (1999) } \\
\text { with positive of anti-islet antibodies result in } \\
\text { inability to produce insulin. }\end{array}$ & Hospital-based & PCR-RFLP & TC, TG \\
\hline Mo et al. [17] & 2011 & $-/ 430$ & - & - & - & $\begin{array}{l}\text { Community-based } \\
\text { and hospital staff }\end{array}$ & PCR-RFLP & $\begin{array}{l}\text { TC,TG, HDL-C, } \\
\text { LDL-C, }\end{array}$ \\
\hline Huang et al. [14] & 2009 & 220/195 & $64.3 \pm 11.1$ & $59.0 \pm 10.1$ & $\begin{array}{l}\text { Patients that diagnosed as CAD according to the } \\
\text { results of clinical symptoms, angiography, } \\
\text { electrocardiogram and echocardiography. }\end{array}$ & Hospital-based & PCR-RFLP & $\mathrm{TC}, \mathrm{TG}$ \\
\hline Wang et al. [19] & 2009 & $45 / 60$ & $51.4 \pm 6.2$ & $52.6 \pm 8.6$ & $\begin{array}{l}\text { Patients diagnosed of CAD based on the criteria of } \\
\text { the World Health Organization (1979). }\end{array}$ & Hospital-based & PCR-RFLP & TC,TG, LDL-C \\
\hline Zhang et al. [23] & 2012 & $675 / 636$ & $56.4 \pm 9.9$ & $55.8 \pm 10.4$ & $\begin{array}{l}\text { Patients diagnosed of CAD based on the criteria of } \\
\text { the World Health Organization (1979). }\end{array}$ & $\begin{array}{l}\text { Community-based } \\
\text { and hospital staff }\end{array}$ & PCR-RFLP & - \\
\hline Ma et al. [16] & 2011 & $112 / 168$ & $57.9 \pm 10.2$ & $56.2 \pm 9.4$ & $\begin{array}{l}\text { Patients that diagnosed as CAD according to the } \\
\text { results of angiography ( } \geq 50 \% \text { stenos in at least one } \\
\text { of the major segments of coronary arteries). }\end{array}$ & Hospital-based & Allele-specific PCR & $\begin{array}{l}\text { TC,TG, HDL-C, } \\
\text { LDL-C }\end{array}$ \\
\hline
\end{tabular}

CAD Coronary artery disease, T2D Type 2 diabetes mellitus, T1D Type 1 diabetes mellitus, PCR Polymerase chain reaction, RFLP Restriction fragment length polymorphism, TC Total cholesterol, TG Triglycerides, HDL-C High-density lipoprotein cholesterol, LDL-C Low-density lipoprotein cholesterol. 
model chosen and susceptibility to outliers, or using random effects models when there was significant heterogeneity but the fixed effects model was analyzed to ensure robustness of the model chosen and susceptibility to outliers. The point estimate of the MD or OR was considered statistically significant at the 2 -tailed $P \leq 0.05$ level. Heterogeneity was analyzed using a chi-square test on $\mathrm{N}-1$ degrees of freedom [25]. $I^{2}$ values of $25 \%, 50 \%$ and $75 \%$ correspond to low, medium and high levels of heterogeneity; respectively. Sensitivity analyses were performed omitting a single study at a time or analyzed another model chosen. If enough studies were identified, funnel plots were to be used to investigate reporting biases [26].

\section{Results}

\section{Characteristics of included studies}

Ten studies [14-23], 5 in English [15,18,20-22] and 5 in Chinese $[14,16,17,19,23]$ met the included criteria for this meta-analysis (Figure 1). All of the studies had been approved by the Ethics Committee of their affiliations, in accordance with the Helsinki Declaration of 1975 as revised in 1983, and all subjects had given informed

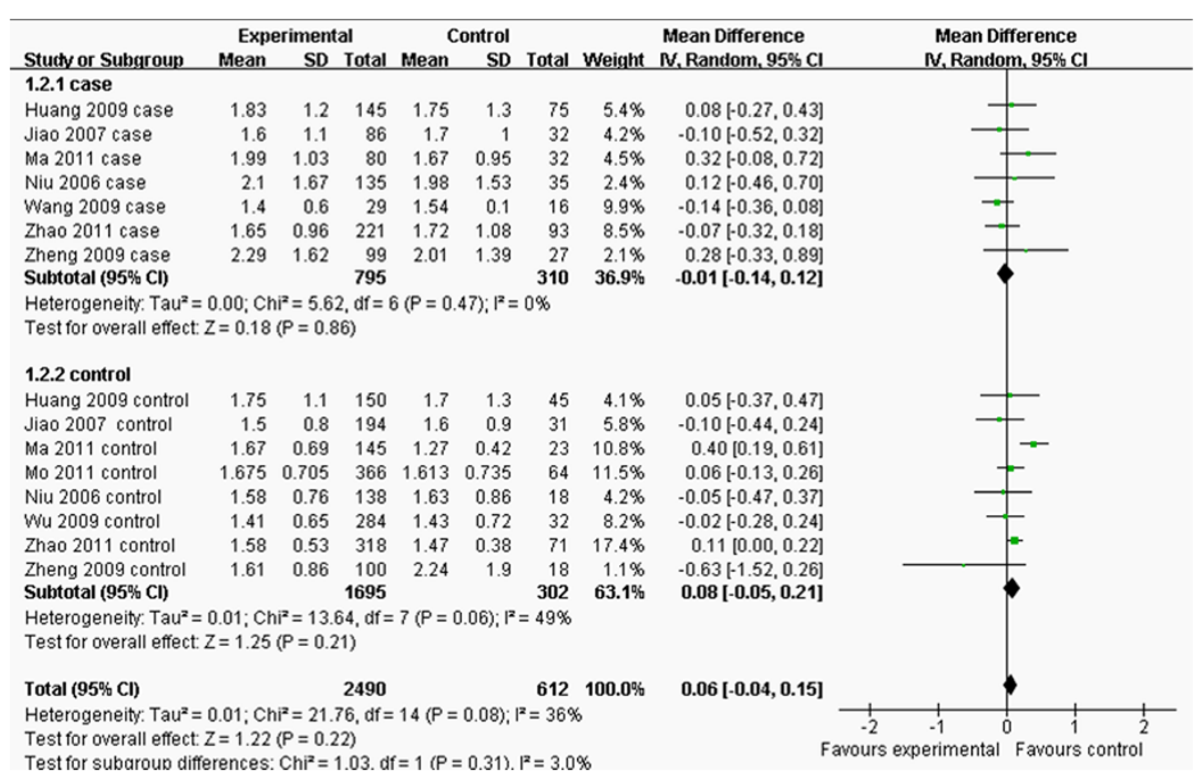

Figure 3 Forest plot of the association between APOM T-778C polymorphism and serum TG levels. (genetic model: $\Pi T$ vs. $C T+C C$ ). 


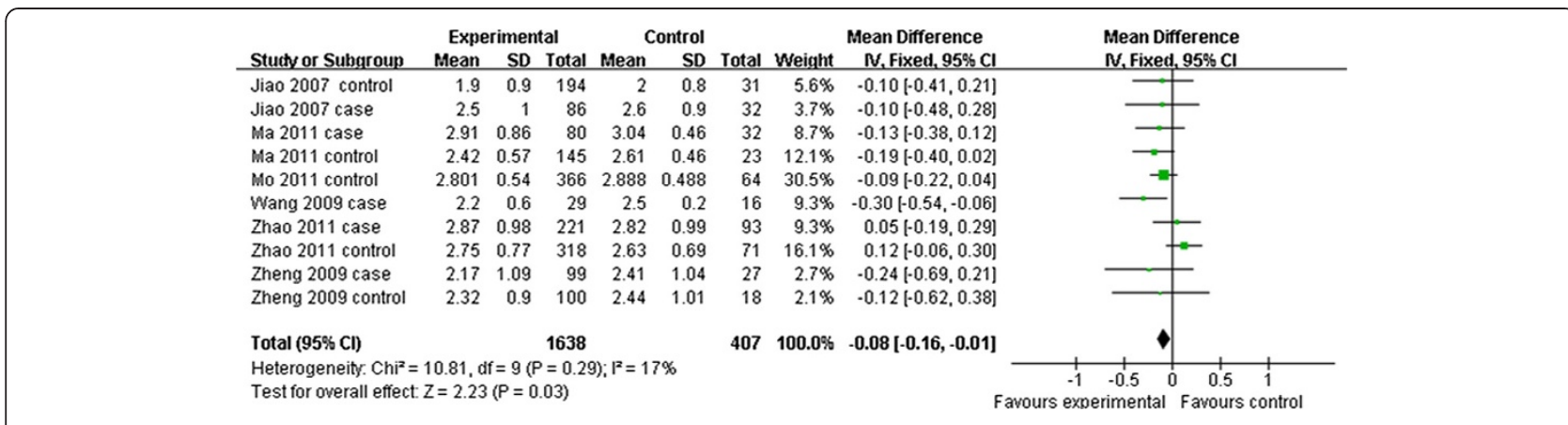

Figure 4 Forest plot of the association between APOM T-778C polymorphism and serum LDL-C levels. (genetic model: $T T$ vs. CT $+C C$ ).

\begin{tabular}{|c|c|c|c|c|c|c|c|c|c|}
\hline \multirow[b]{2}{*}{ Stucty or Subgroup } & \multicolumn{3}{|c|}{ Experimental } & \multicolumn{2}{|c|}{ Control } & \multirow[b]{2}{*}{ Total } & \multirow[b]{2}{*}{ Weight } & \multirow{2}{*}{$\begin{array}{l}\text { Mean Difference } \\
\text { N. Fixed, 95\% Cl }\end{array}$} & \multirow{2}{*}{$\begin{array}{l}\text { Mean Difference } \\
\text { N. Fixed, } 95 \% \mathrm{Cl}\end{array}$} \\
\hline & Mean & SD & Total & Mean & SD & & & & \\
\hline Jiao 2007 control & 1.1 & 0.4 & 194 & 1.1 & 0.4 & 31 & $4.3 \%$ & $0.00[-0.15,0.15]$ & \\
\hline Jiao 2007 case & 1.1 & 0.3 & 86 & 1.1 & 0.4 & 32 & $4.3 \%$ & $0.00[-0.15,0.15]$ & \\
\hline Ma 2011 case & 1.11 & 0.27 & 80 & 1.16 & 0.27 & 32 & $8.1 \%$ & $-0.05[-0.16,0.06]$ & \\
\hline Ma 2011 control & 1.12 & 0.19 & 145 & 1.17 & 0.17 & 23 & $17.2 \%$ & $-0.05[-0.13,0.03]$ & \\
\hline Mo 2011 control & 1.4 & 0.321 & 366 & 1.317 & 0.246 & 64 & $21.1 \%$ & $0.08[0.01,0.15]$ & - \\
\hline Zhao 2011 case & 1.36 & 0.36 & 221 & 1.35 & 0.34 & 93 & $14.2 \%$ & $0.01[-0.07,0.09]$ & \\
\hline Zhao 2011 control & 1.34 & 0.24 & 318 & 1.36 & 0.27 & 71 & $21.5 \%$ & $-0.02[-0.09,0.05]$ & \\
\hline Zheng 2009 case & 1.12 & 0.41 & 99 & 1.11 & 0.27 & 27 & $5.9 \%$ & $0.01[-0.12,0.14]$ & \\
\hline Zheng 2009 control & 1.2 & 0.3 & 100 & 1.32 & 0.35 & 18 & $3.4 \%$ & $-0.12[-0.29,0.05]$ & \\
\hline Total $(95 \% \mathrm{Cl})$ & & & 1609 & & & 391 & $100.0 \%$ & $-0.00[-0.03,0.03]$ & \\
\hline \multicolumn{6}{|c|}{$\begin{array}{l}\text { Heterogeneity. Chi }{ }^{2}=10.33, d f=8(P=0.24) ; I^{2}=23 \% \\
\text { Test for overall effect } Z=0.09(P=0.93)\end{array}$} & & & & $\begin{array}{lll}5-0.25 & 0 & 0.25 \\
\text { erimental } & \text { Favour }\end{array}$ \\
\hline
\end{tabular}

Figure 5 Forest plot of the association between APOM T-778C polymorphism and serum HDL-C levels. (genetic model: $\Pi T$ vs. $C T+C C$ ).

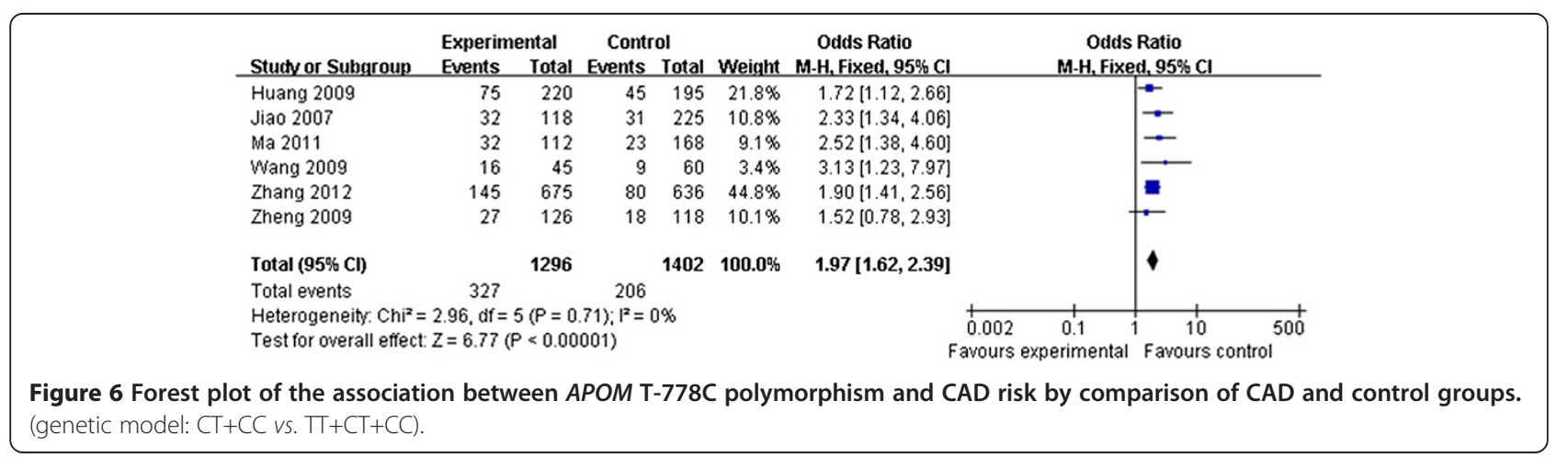


Table 3 Quality assessment for all the included studies of the CAD

\begin{tabular}{|c|c|c|c|c|}
\hline First author & Publishing year & Selection & Comparability & Exposure \\
\hline Jiao [15] & 2007 & 论论败 & 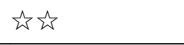 & 论地场 \\
\hline Huang [14] & 2009 & 论论访 & - & 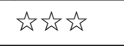 \\
\hline Zheng [22] & 2009 & 论施访 & is & 动动动 \\
\hline Ma [16] & 2011 & 论沶 & $\hat{s}$ & 论沶 \\
\hline Zhang [23] & 2012 & 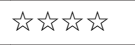 & - & 论沶 \\
\hline Wang [19] & 2009 & 论弥弥 & - & 证弥 \\
\hline
\end{tabular}

consent. The present study was approved by the Ethics Committee of the First Affiliated Hospital, Guangxi Medical University. Among them, six of the eligible studies contained data in lipid parameters on two different groups [14-16,18,21,22], and we treated the different groups as independent. Therefore, a total of 16 separate comparisons were finally included in our meta-analysis.

The main characteristics of each study are shown in Table 2. Nine studies contained the data of TG and TC and there were 15 separated comparisons; six studies contained the levels of LDL-C and there were 10 separated comparisons; five studies included the concentrations of HDL-C and there were 9 separated comparisons; and six studies contained the data of CAD for this metaanalysis (Figures 2, 3, 4, 5 and 6). A total of 4,413 people were included in this study. The relationship between lipid parameters and genotypes in 3,102 people, and between the risk of CAD and genotypes in 2,698 subjects was analyzed; respectively. All the eligible studies were conducted in the Chinese population.

The quality of all included studies was assessed by NOS (Table 3). Most studies were of medium or high quality in terms of selection and exposure. However, as for comparability, the quality was relativity low, since some of confounders didn't be adjusted for the analysis.

\section{Frequencies of the genotype}

Frequencies of the APOM T-778C genotypes in each group and all $P$-values of HWE testing are shown in Table 4. The genotype distribution of the APOM T-778C polymorphism in all eligible studies was consistent with HWE $(P>0.05)$.

\section{Outcomes of lipid levels}

As shown in Figure 2, the pooled effects indicated that $\mathrm{CT}+\mathrm{CC}$ group had higher levels of TC than TT group (MD:-0.36, 95\% CI: $-0.53--0.19, P<0.0001$; heterogeneity test $\left.x^{2}=56.34, P<0.00001, I^{2}=75 \%\right)$. There was no difference in the levels of TG between TT and CT+CC groups (MD: 0.06, 95\% CI: $-0.04-0.15, P=0.22$; heterogeneity test $x^{2}=21.76, P=0.08, I^{2}=36 \%$; Figure 3$)$. CT+CC group had higher levels of LDL-C than TT group (MD: -0.08, 95\% CI: $-0.16--0.01, P=0.03$; heterogeneity test $x^{2}=10.81, P=0.29, I^{2}=17 \%$; Figure 4$)$. There was no difference in the levels of HDL-C between TT and CT+CC groups (MD: 0.00, 95\% CI: $-0.03-0.03, P=0.93$; heterogeneity test $x^{2}=10.33, P=0.24, I^{2}=23 \%$; Figure 5).

\section{Outcomes of the risk of CAD}

The eligible compared groups were pooled with fixed effects models and the data of $\mathrm{CT}+\mathrm{CC}$ and $\mathrm{CC}+\mathrm{CT}+\mathrm{TT}$ groups in the $\mathrm{CAD} /$ control value and the pooled effects are shown in Figure 6. Pooled effects showed that CAD group had higher $\mathrm{CT}+\mathrm{CC}$ genetype frequency than control group (OR: 1.97, 95\% CI: 1.62-2.39, $P<0.00001$; heterogeneity test $\left.x^{2}=2.96, P=0.71, I^{2}=0 \%\right)$.

\section{Sensitivity analysis}

Sensitivity analyses were performed to assess the contribution of each study to the pooled estimate and by excluding individual studies one at a time and recalculating the pooled MD or OR estimates for the remaining studies.

Table 4 Genotypic frequency of APOM T-778C polymorphisms in different populations included in the meta-analysis

\begin{tabular}{|c|c|c|c|c|c|c|c|c|}
\hline \multirow{2}{*}{ Study } & \multirow{2}{*}{ Year } & \multicolumn{3}{|c|}{ Case (\%) } & \multicolumn{3}{|c|}{ Control (\%) } & \multirow{2}{*}{$\begin{array}{c}\text { P-Value for } \\
\text { Hardy-Weinberg } \\
\text { equilibrium }\end{array}$} \\
\hline & & $\mathrm{TT}$ & CT & $\mathrm{CC}$ & TT & CT & $\mathrm{TT}$ & \\
\hline Jiao et al. [15] & 2007 & $86(72.9)$ & $29(24.6)$ & $3(2.5)$ & $194(86.2)$ & 31 (13.8) & $0(0.0)$ & 0.267 \\
\hline Zhao et al. [21] & 2011 & $221(70.4)$ & $86(27.4)$ & $7(2.2)$ & 318 (81.7) & $67(17.3)$ & $4(1.0)$ & 0.823 \\
\hline Zheng et al. [22] & 2009 & $99(78.6)$ & $25(19.8)$ & $2(1.6)$ & $100(84.7)$ & $18(15.3)$ & $0(0.0)$ & 0.370 \\
\hline Niu et al. [18] & 2006 & $135(79.4)$ & $34(20.0)$ & $1(0.6)$ & $138(88.5)$ & $18(11.5)$ & $0(0.0)$ & 0.444 \\
\hline Wu et al. [20] & 2009 & $140(79.1)$ & $37(20.9)$ & $0(0.0)$ & $284(89.9)$ & $32(10.1)$ & $0(0.0)$ & 0.358 \\
\hline Mo et al. [17] & 2011 & - & - & - & $366(85.1)$ & $62(14.4)$ & $2(0.05)$ & 0.717 \\
\hline Huang et al. [14] & 2009 & $145(65.9)$ & $66(30.0)$ & $9(0.41)$ & $150(76.9)$ & $41(21.0)$ & $4(2.1)$ & 0.548 \\
\hline Wang et al. [19] & 2009 & $29(64.4)$ & $15(33.3)$ & $1(2.2)$ & $51(85.0)$ & $9(15.0)$ & $0(0.0)$ & 0.530 \\
\hline Zhang et al. [23] & 2012 & $530(78.5)$ & $135(20.0)$ & $10(1.5)$ & $556(87.5)$ & $74(11.6)$ & $6(0.9)$ & 0.052 \\
\hline Ma et al. [16] & 2011 & $80(71.4)$ & $30(26.8)$ & $2(1.8)$ & $145(86.3)$ & $21(12.5)$ & $2(1.2)$ & 0.231 \\
\hline
\end{tabular}




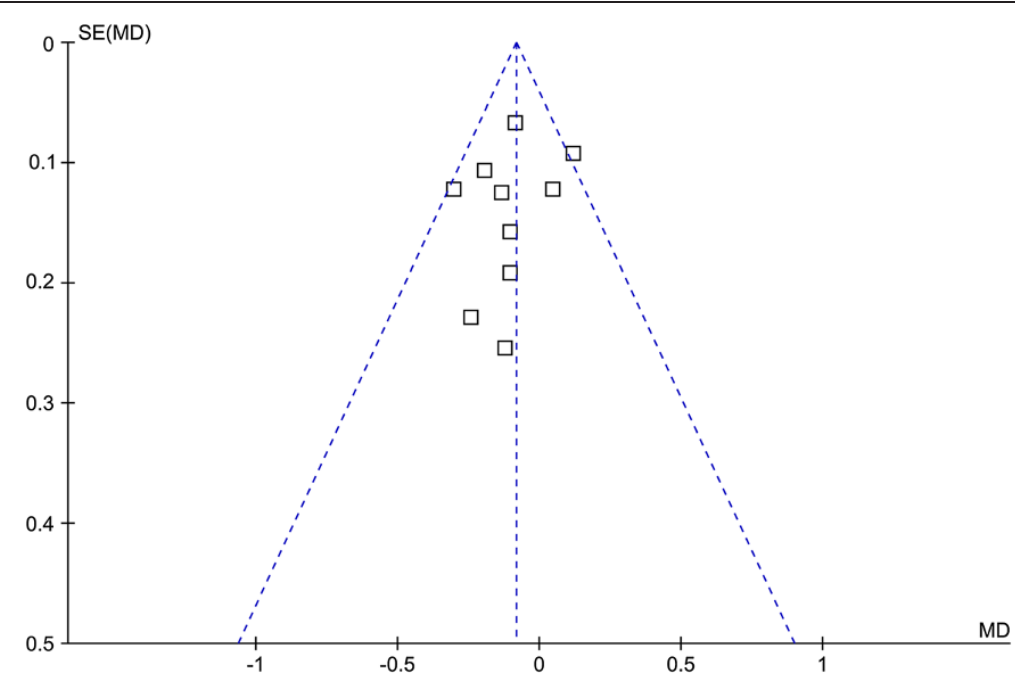

Figure 7 Funnel plot of the association between APOM T-778C polymorphism and serum LDL-C levels. (genetic model: $T T$ vs. CT + CC)

Eliminating the studies with more than 300 patients or less than 100 patients in each group did not substantially change the pooled point estimate, which indicates the reliability of our results. What is more, performing transition of model also did not substantially change the pooled point estimate.

\section{Heterogeneity analysis}

For the outcomes of TC, the $I^{2}$ value of heterogeneity was greater than $50 \%$ and the heterogeneity test: $P$ value was less than 0.10 in model TT vs. CT $+\mathrm{CC}$ in the overall populations, which indicated statistically significant heterogeneity among the studies. In order to explore the sources of heterogeneity, the studies were stratified by cases and controls and subgroup analyses were performed.
However, heterogeneity still existed in the outcomes of TC (Figure 2).

\section{Publication bias}

The funnel plot and Egger test were performed to assess the publication bias of literatures in all comparison models. No visual publication bias was found in the funnel plot (Figures 7 and 8).

\section{Discussion}

Association of different genes in relation to the predisposition of $\mathrm{CAD}$ has been widely examined. It may conclude that CAD is both multifactorial and polygenic in nature. The disorders of lipid profile are important risk factors involved in this process [27]. A variety of

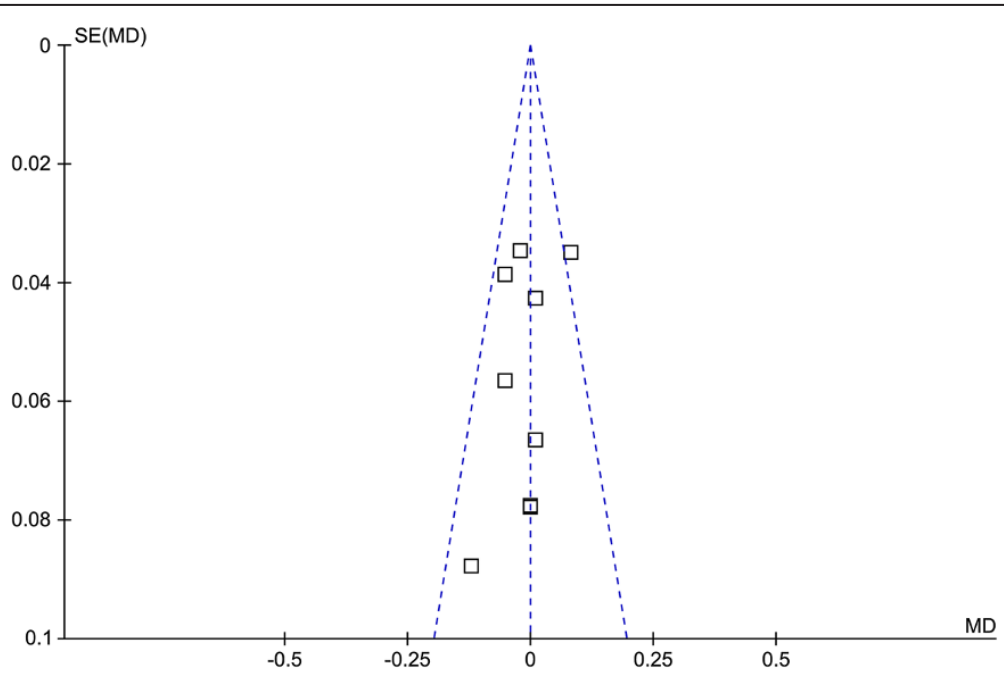

Figure 8 Funnel plot of the association between APOM T-778C polymorphism and serum HDL-C levels. (genetic model: $\Pi T$ vs. $C T+C C$ ) 
candidate genes have been investigated as predisposing factors of CAD, including those involved in lipid metabolisms. ApoM is one of the latest additions to the apolipoprotein family [28]. Over expression of ApoM had a protective effect against atherosclerosis [12]. Many investigators carried out case-control studies in order to determine the association between this polymorphism and serum lipid levels or the risk of CAD, but the results are inconclusive. This may be due to a small sample size. The characteristic of a meta-analysis is to obtain a more competitive result by combining the comparable studies, increasing the sample size and statistical power [29].

The results of our meta-analysis showed that the $\mathrm{CT}+\mathrm{CC}$ group had higher levels of TC and LDL-C than the TT group, and there was no difference in the levels of HDL-C and TG between the TT and CT+CC groups. Moreover, the $\mathrm{CT}+\mathrm{CC}$ genotype was associated with increased risk of CAD.

In the present study, we included ten studies and all of the subjects were the Chinese populations. Baseline characteristics of two comparison groups of included studies were substantially similar. All included studies were consistent with HWE. The quality of the included studies that associated between polymorphism and CAD risk was assessed by NOS and most studies were of medium or high quality. In addition, heterogeneities of pooled effects of HDL-C, LDL-C and CAD were low. MD of total of TC $(P<0.0001)$ and OR of total of CAD risk $(P<0.00001)$ were large effect. All these made our conclusion more robust.

Heterogeneity analysis showed that the polymorphism suggested significant heterogeneity in the outcomes of TC in the overall populations. To explore the sources of heterogeneity, we performed subgroup analyses, but heterogeneity still existed in the outcomes of TC. This may be due to China being a large country with multiethnic country. Different groups of the included studies had different genetic background and environmental factors. It is well known that both serum lipid levels and CAD are affected by genetic and environmental factors, such as dietary patterns, lifestyle, obesity, physical inactivity. Moreover, pharmaceuticals, age, gender, hypertension are also associated with serum lipid levels [30].

Some limitations of this meta-analysis should be discussed. First, this meta-analysis focused only on papers published in English and Chinese and the ones that reported in other languages may bias the present results. Second, the meta-analysis cannot be corrected the bias of each study in the outcomes of TC, and may generate a statistical conclusion with more power and precision. In addition, gene-gene and gene-environment interactions should also be considered in the analysis.

Therefore, it is necessary to conduct large sample studies using standardized unbiased genotyping methods, homogeneous CAD patients and well- matched controls. Moreover, gene-gene and gene-environment interactions should also be considered in the analysis. Such studies taking these factors into account may eventually lead to better, more comprehensive understanding of the association between the APOM T-778C polymorphism and serum lipid levels or the risk of CAD.

\section{Conclusion}

The results of the current meta-analysis showed that the $\mathrm{CT}+\mathrm{CC}$ group had higher levels of TC and LDL than the TT group, and there was no difference in the levels of HDL and TG between the TT and $\mathrm{CT}+\mathrm{CC}$ groups. Moreover, there a prominent association between the APOM T-778C polymorphism and the risk of CAD in the Chinese population, and the $\mathrm{CT}+\mathrm{CC}$ genotype was associated with increased risk of CAD.

Competing interests

The authors declare that they have no competing interests.

\section{Authors' contributions}

ZZ and GC conceived the study, participated in the design, collected the data, performed statistical analyses, and drafted the manuscript. RXY conceived the study, participated in the design, and helped to draft the manuscript. All authors read and approved the final manuscript.

\section{Acknowledgments}

This study was supported by the National Natural Science Foundation of China (No: 81200205 and No: 30960130).

\section{Author details}

${ }^{1}$ Department of Cardiology, Institute of Cardiovascular Diseases, The First Affiliated Hospital, Guangxi Medical University, Nanning 530021, Guangxi, People's Republic of China. ${ }^{2}$ Department of Cardiology, Shanghai First People's Hospital, Shanghai Jiao Tong University School of Medicine, Shanghai 200080, People's Republic of China.

Received: 6 May 2013 Accepted: 6 June 2013

Published: 16 September 2013

\section{References}

1. McGovern PG, Pankow JS, Shahar E, Doliszny KM, Folsom AR, Blackburn H, Luepker RV: Recent trends in acute coronary heart disease-mortality, morbidity, medical care, and risk factors. The Minnesota Heart Survey Investigators. N Engl J Med 1996, 334:884-890.

2. Castelli WP, Garrison RJ, Wilson PW, Abbott RD, Kalousdian S, Kannel WB: Incidence of coronary heart disease and lipoprotein cholesterol levels. The Framingham Study. JAMA 1986, 256:2835-2838.

3. Wilson PW, D'Agostino RB, Levy D, Belanger AM, Silbershatz H, Kannel WB: Prediction of coronary heart disease using risk factor categories. Circulation 1998, 97:1837-1847.

4. Shekelle RB, Shryock AM, Paul O, Lepper M, Stamler J, Liu S, Raynor WJ Jr: Diet, serum cholesterol, and death from coronary heart disease. The Western Electric study. N Engl J Med 1981, 304:65-70.

5. Hokanson JE, Austin MA: Plasma triglyceride level is a risk factor for cardiovascular disease independent of high-density lipoprotein cholesterol level: a meta-analysis of population-based prospective studies. J Cardiovasc Risk 1996, 3:213-219.

6. Marz W, Scharnagl H, Winkler K, Tiran A, Nauck M, Boehm BO, Winkelmann BR: Low-density lipoprotein triglycerides associated with low-grade systemic inflammation, adhesion molecules, and angiographic coronary artery disease: the Ludwigshafen Risk and Cardiovascular Health study. Circulation 2004, 110:3068-3074. 
7. Durrington PN, Hunt L, Ishola M, Kane J, Stephens WP: Serum apolipoproteins Al and B and lipoproteins in middle aged men with and without previous myocardial infarction. Br Heart J 1986, 56:206-212.

8. Kwiterovich PO Jr, Coresh J, Smith HH, Bachorik PS, Derby CA, Pearson TA: Comparison of the plasma levels of apolipoproteins $B$ and $A-1$, and other risk factors in men and women with premature coronary artery disease. Am J Cardiol 1992, 69:1015-1021.

9. Heller DA, De Faire U, Pedersen NL, Dahlen G, McClearn GE: Genetic and environmental influences on serum lipid levels in twins. $N$ Engl J Med 1993, 328:1150-1156.

10. Visvikis-Siest S, Marteau JB: Genetic variants predisposing to cardiovascular disease. Curr Opin Lipidol 2006, 17:139-151.

11. Xie T, Rowen L, Aguado B, Ahearn ME, Madan A, Qin S, Campbell RD, Hood $L$ : Analysis of the gene-dense major histocompatibility complex class III region and its comparison to mouse. Genome Res 2003, 13:2621-2636.

12. Wolfrum C, Poy MN, Stoffel M: Apolipoprotein M is required for prebeta$\mathrm{HDL}$ formation and cholesterol efflux to $\mathrm{HDL}$ and protects against atherosclerosis. Nat Med 2005, 11:418-422.

13. Luo G, Zhang X, Nilsson-Ehle P, Xu N: Apolipoprotein M. Lipids Health Dis 2004, 3:21.

14. Huang B, Zhang S, Huang YH, Han F, Zheng YY, Jiang J: A study on the associativity of apolipoprotein $\mathrm{M}$ gene pormoter T-778 C polymorphism with coronary heart disease among Han people of Guizhou. Journal of Guiyang Medical College 2009, 34(3):297-299.

15. Jiao GQ, Yuan ZX, Xue YS, Yang CJ, Lu CB, Lu ZQ, Xiao MD: A prospective evaluation of apolipoprotein $\mathrm{M}$ gene $\mathrm{T}-778 \mathrm{C}$ polymorphism in relation to coronary artery disease in Han Chinese. Clin Biochem 2007, 40:1108-1112.

16. Ma L, Li B, Wang $X$ : The study on the interrelation between polymorphism of apolipoprotein $\mathrm{M}$ and in the ratio of apoB/apoAl patients with coronary heart disease. China Modern Medicine 2011, 18:42-43.

17. Mo $Y$, Huang $Y$, Huang J: The relationship between apolipoprotein $M$ gene polymorphism and serum lipids in Han, Miao and Buyi nationalities of Guizhou Province. Journal of Guiyang Medical College 2011, 36:477-480.

18. Niu N, Zhu X, Liu Y, Du T, Wang X, Chen D, Sun B, Gu HF: Single nucleotide polymorphisms in the proximal promoter region of apolipoprotein $M$ gene (apoM) confer the susceptibility to development of type 2 diabetes in Han Chinese. Diabetes Metab Res Rev 2007, 23:21-25.

19. Wang $X, L i B$ : Discussion of the relationship between apoM genotype and lipoprotein (a) in patients of coronary heart disease. Chinese Journal of Integrative Medicine on Cardio-/Cerebrovascular Disease 2009, 7:654-656.

20. Wu X, Niu N, Brismar K, Zhu X, Wang X, Efendic S, Du T, Liu Y, Gu HF: Apolipoprotein $\mathrm{M}$ promoter polymorphisms alter promoter activity and confer the susceptibility to the development of type 1 diabetes. Clin Biochem 2009, 42:17-21.

21. Zhao D, He Z, Qin X, Li L, Liu F, Deng S: Association of apolipoprotein M gene polymorphisms with ischemic stroke in a Han Chinese population. J Mol Neurosci 2010, 43:370-375.

22. Zheng L, Luo G, Zhang X, Zhang J, Zhu J, Wei J, Mu Q, Chen L, Nilsson-Ehle $\mathrm{P}, \mathrm{Xu}$ N: Determination of single-nucleotide polymorphism in the proximal promoter region of apolipoprotein $\mathrm{M}$ gene in coronary artery diseases. Int J Gen Med 2009, 2:177-182.

23. Zhang X, Liu T, Cai W, Yan C, Liang Z, Sun Y, Feng X, Han Y: Polymorphisms in the ApoM gene confer the susceptibility to acute coronary syndrome. Shan Dong Yi Yao 2012, 52:1-3.

24. Egger M, Davey Smith G, Schneider M, Minder C: Bias in meta-analysis detected by a simple, graphical test. BMJ 1997, 315:629-634.

25. Higgins JP, Thompson SG, Deeks JJ, Altman DG: Measuring inconsistency in meta-analyses. BMJ 2003, 327:557-560

26. Cochrane Handbook for Systematic Reviews of Interventions Version 5.0.0 [updated February 2008]. The Cochrane Collaboration. Edited by Higgins JPTGS; 2008. Available from www.cochrane-handbook.org. 2008.

27. Whitney EJ, Krasuski RA, Personius BE, Michalek JE, Maranian AM, Kolasa MW, Monick E, Brown BG, Gotto AM Jr: A randomized trial of a strategy for increasing high-density lipoprotein cholesterol levels: effects on progression of coronary heart disease and clinical events. Ann Intern Med 2005, 142:95-104.
28. Xu N, Dahlback B: A novel human apolipoprotein (apoM). J Biol Chem 1999, 274:31286-31290.

29. Lohmueller KE, Pearce CL, Pike M, Lander ES, Hirschhorn JN: Meta-analysis of genetic association studies supports a contribution of common variants to susceptibility to common disease. Nat Genet 2003, 33:177-182.

30. Ruixing Y, Qiming F, Dezhai Y, Shuquan L, Weixiong L, Shangling P, Hai W, Yongzhong $Y$, Feng $H$, Shuming Q: Comparison of demography, diet, lifestyle, and serum lipid levels between the Guangxi Bai Ku Yao and Han populations. J Lipid Res 2007, 48:2673-2681.

doi:10.1186/1476-511X-12-135

Cite this article as: Zhang et al: Apolipoprotein M T-778C polymorphism is associated with serum lipid levels and the risk of coronary artery disease in the Chinese population: a meta-analysis. Lipids in Health and Disease 2013 12:135.

\section{Submit your next manuscript to BioMed Central and take full advantage of:}

- Convenient online submission

- Thorough peer review

- No space constraints or color figure charges

- Immediate publication on acceptance

- Inclusion in PubMed, CAS, Scopus and Google Scholar

- Research which is freely available for redistribution

Submit your manuscript at www.biomedcentral.com/submit
C Biomed Central 